\title{
Imaging Appearances of Autoimmune Pancreatitis
}

\author{
Koji Takeshita \\ Teikyo University School of Medicine, \\ Japan
}

\section{Introduction}

Autoimmune pancreatitis (AIP) is a rare disorder of presumed autoimmune etiology with specific pathologic features, and is an increasingly recognized clinical condition. AIP is characterized histologically by fibrosis with dense infiltration of T lymphocytes and IgG4positive plasma cells in the peripancreatic and interlobular area of the pancreas (1-4). Patients with AIP usually have serum markers of autoimmune disorders, such as increased IgG4 and antinuclear antibodies. Although clinical features and symptoms are nonspecific, association with many other autoimmune disorders have also been reported (5-10). Therefore AIP should be considered in differential diagnosis when a patient with another autoimmune condition presents with symptoms related to the pancreas and biliary tract.

AIP has been described in literature to respond well to steroid therapy. Also, imaging appearances of AIP improve with steroid therapy, so imaging can be used in evaluation of treatment (11-16). Correct diagnosis is essential for appropriate treatment planning and to avoid unnecessary surgery. In particular, differentiation of AIP from pancreatic malignancies is very important, and several characteristic imaging features have been reported (16-18).

This article presents imaging appearances of AIP described in several radiological publications.

\section{Imaging findings of AIP}

AIP is mainly indicated by an imaging procedure such as contrast enhanced computed tomography (CT) or magnetic resonance imaging (MRI) $(16,18-22)$.

The classic finding of contrast enhanced CT that is diagnostic or highly suggestive of AIP is the diffuse sausage shaped enlargement of the entire pancreas with homogeneous attenuation, moderate enhancement and featureless, pencil sharp borders, absent of the normal pancreatic clefts (Figure1-4). The pancreas is covered with a thin capsular-like low density rim that possibly represents inflammatory exudates (Fig 1ab). Usually there is no calcification, peripancreatic fluid collection or vascular involvement. Though the diffuse form is most commonly reported in literature, focal forms have been reported, and the involved segment may mimic a pancreatic tumor, consequently most patients with focal forms of AIP underwent surgery, because of preoperative diagnoses of pancreatic carcinoma (Figure 4)(16-18, 23, 24). 


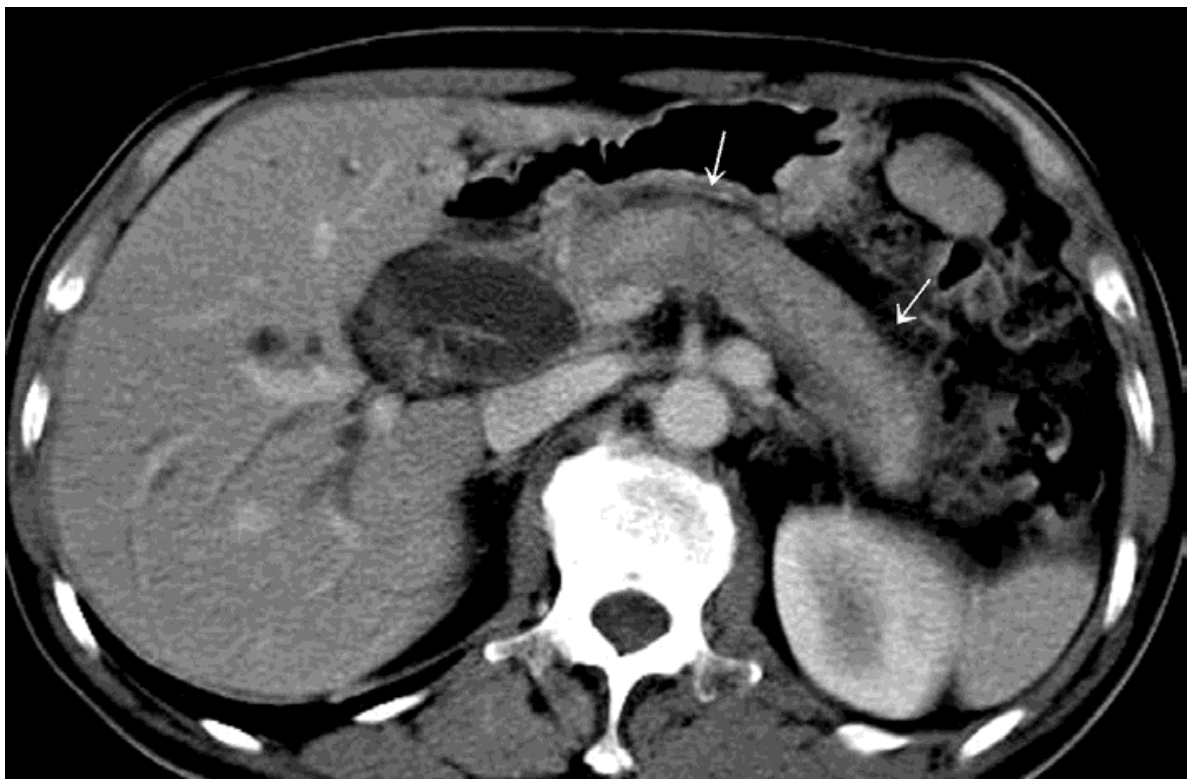

A

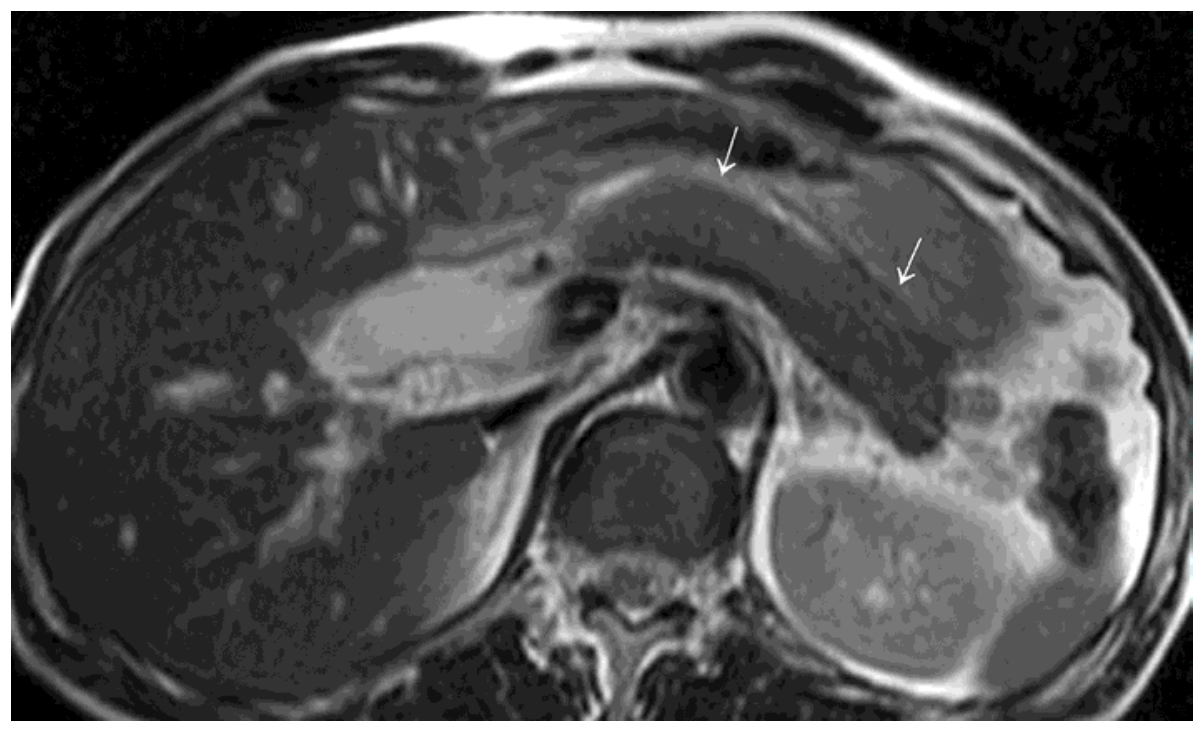

B

A, Contrast enhanced axial CT scan shows diffuse enlargement of the pancreas with sharp borders and minimal peripancreatic stranding (arrow), B, MRI shows diffuse pancreatic enlargement with minimal high signal intensity on T2-weighted MR images.

Fig. 1. (A,B) Images obtained in 58-year-old man with diffuse form of AIP who had jaundice and abdominal pain at presentation. 


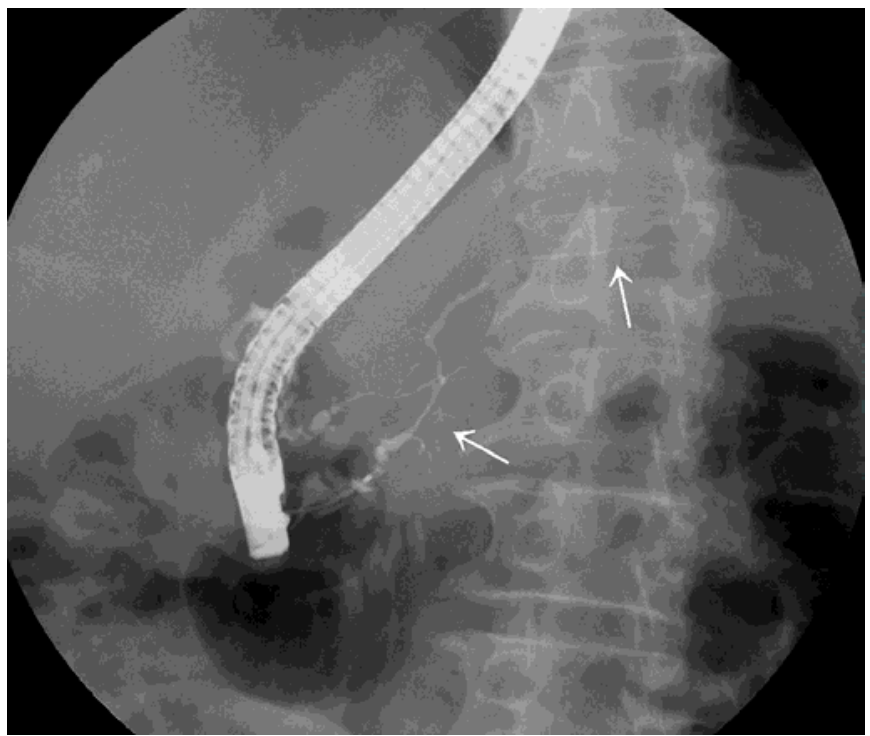

C

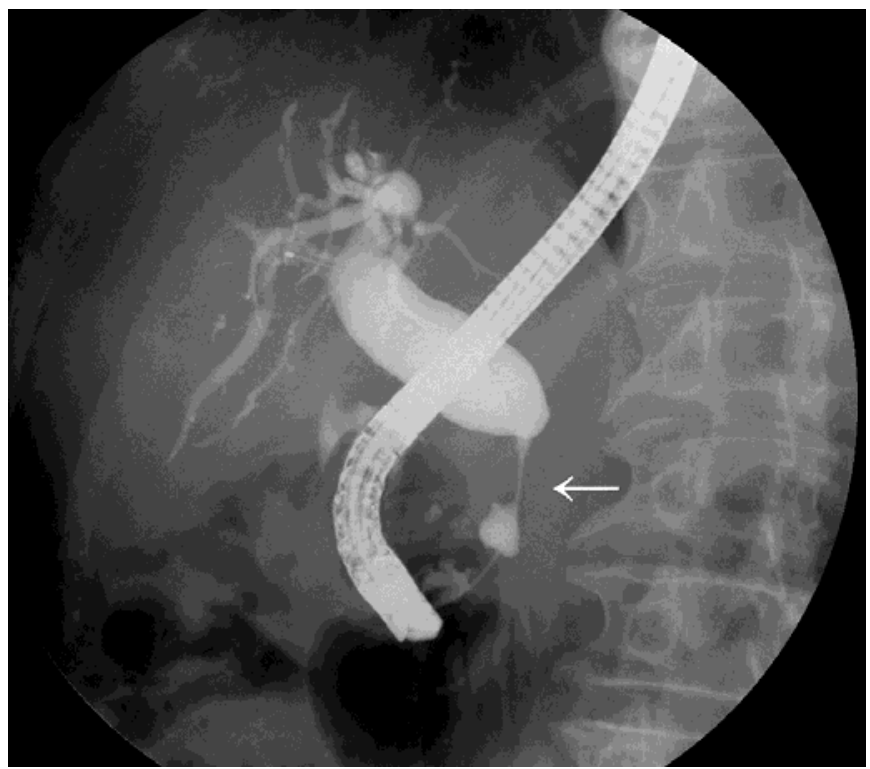

$\mathrm{D}$

Endoscopic retrograde cholangiopancreatographic (ERCP) image shows diffuse narrowing of pancreatic duct with irregular walls (C; arrrows), and focal stricture in distal common bile duct (D; arrrow).

Fig. 1. (C,D) Images obtained in 58-year-old man with diffuse form of AIP who had jaundice and abdominal pain at presentation. 


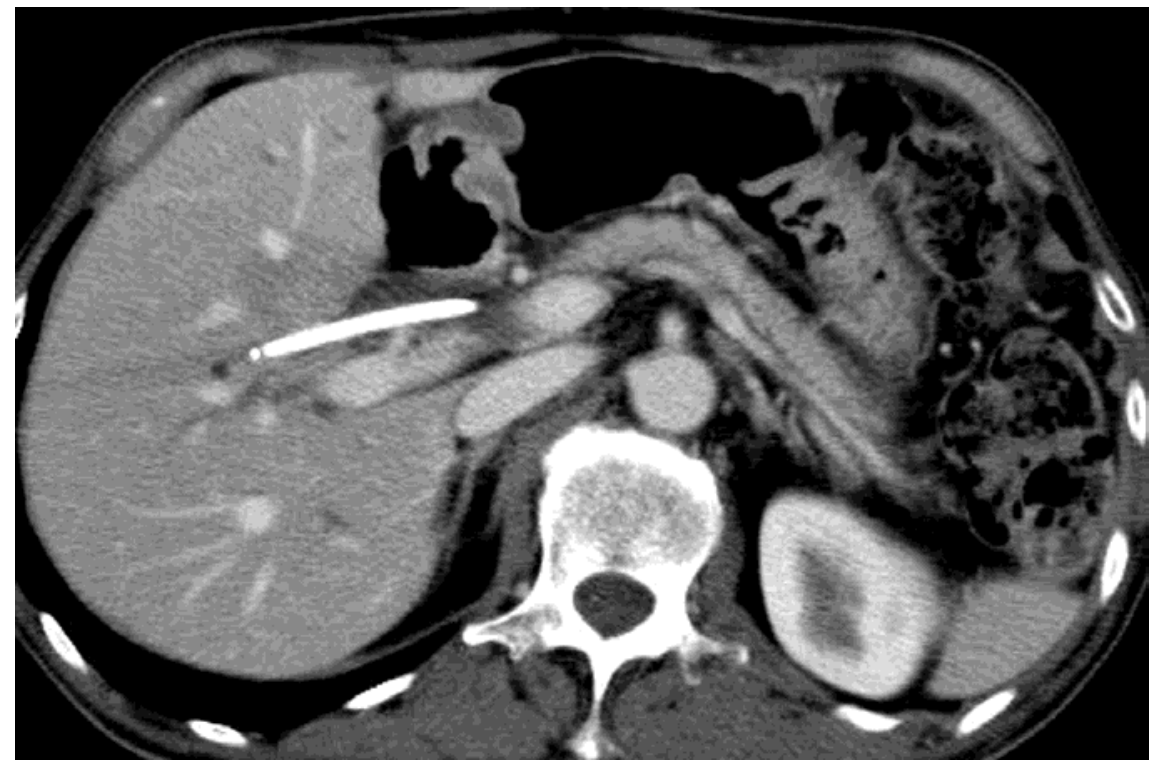

E

E, Axial CT scan shows that enlargement of the pancreas diminished after steroid therapy.

Fig. 1. (E) Images obtained in 58-year-old man with diffuse form of AIP who had jaundice and abdominal pain at presentation.

A diffusely enlarged pancreas can be also seen in diffuse infiltrative pancreatic carcinoma, malignant lymphoma, plasmacytoma, or metastases. However, in most of these conditions, imaging features are usually different from those observed in AIP.

Compared with normal pancreatic parenchyma, diffuse or localized enlargement of the pancreas is seen as low intensity on T1-weighted MR images and high intensity on T2weighted images (Figure1b). Diffusion-weighted MR images (DWI) are considered useful for detecting AIP and for evaluating the effect of steroid therapy. AIP is seen as high signal intensity on DWI (Figure4c), which improved after steroid treatment. Apparent diffusion coefficients (ADCs) also reflected disease activity (Fiure4d). Thus, DWI is considered a valuable tool for detecting AIP, determining the affected area, and evaluating the effect of treatment $(25,26)$. In many cases, ADC values are lower in AIP than in pancreatic cancer, so an ADC cut off value is potentially useful for distinguishing AIP from pancreatic cancer (26).

Magnetic resonance cholangiopancreatography $(\mathrm{MRCP})$ is a non-invasive method to evaluate the pancreatic duct and biliary tract, and recently, the imaging quality has increased to almost the equivalent of endoscopic retrograde cholangiopancreatography (ERCP). ERCP is thought to be the most accurate diagnostic modality for AIP, especially when evaluating the pancreatic duct (27). Both MRCP and ERCP show characteristic diffuse narrowing with irregularities or serration along various segments of the main pancreatic duct (Figure1c, 3d). Sometimes, there may be a focal stricture. The intrapancreatic segment of the common bile duct may be focally or segmentally narrowed resulting in dilatation of the proximal bile duct (Figure1d, 3d). 


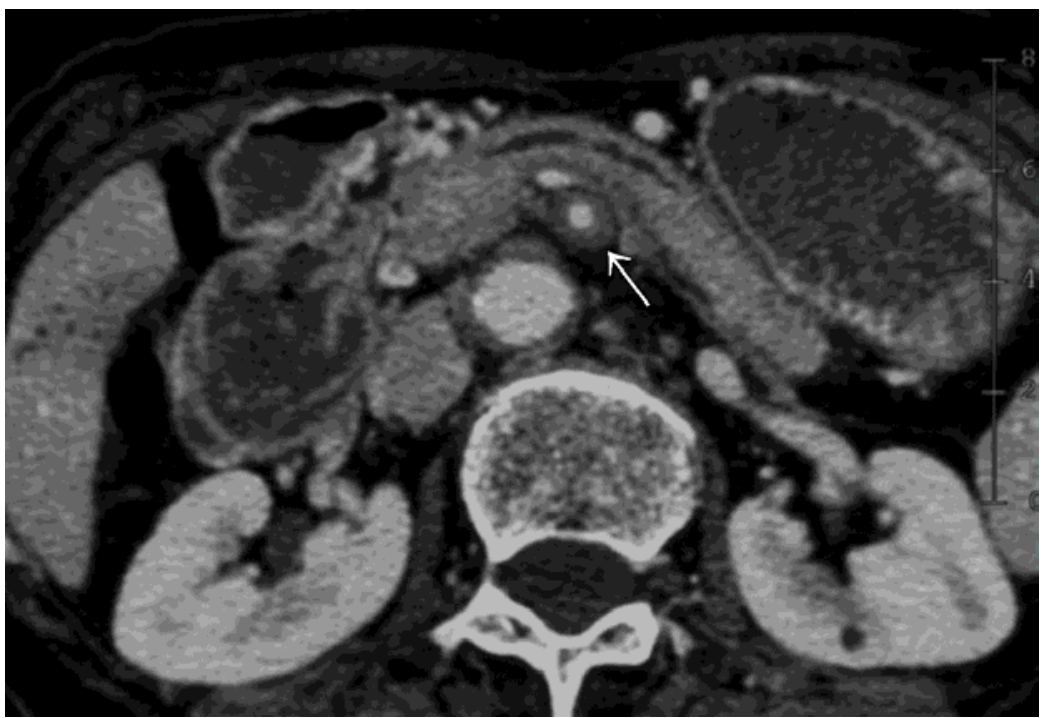

Axial CT scan obtained at the level of the proximal portion of superior mesenteric artery shows circumferential thickening of periarterial soft tissue (arrow) consistent with sclerosing messenteritis.

Fig. 2. 52-year-old man with diffuse form of AIP.

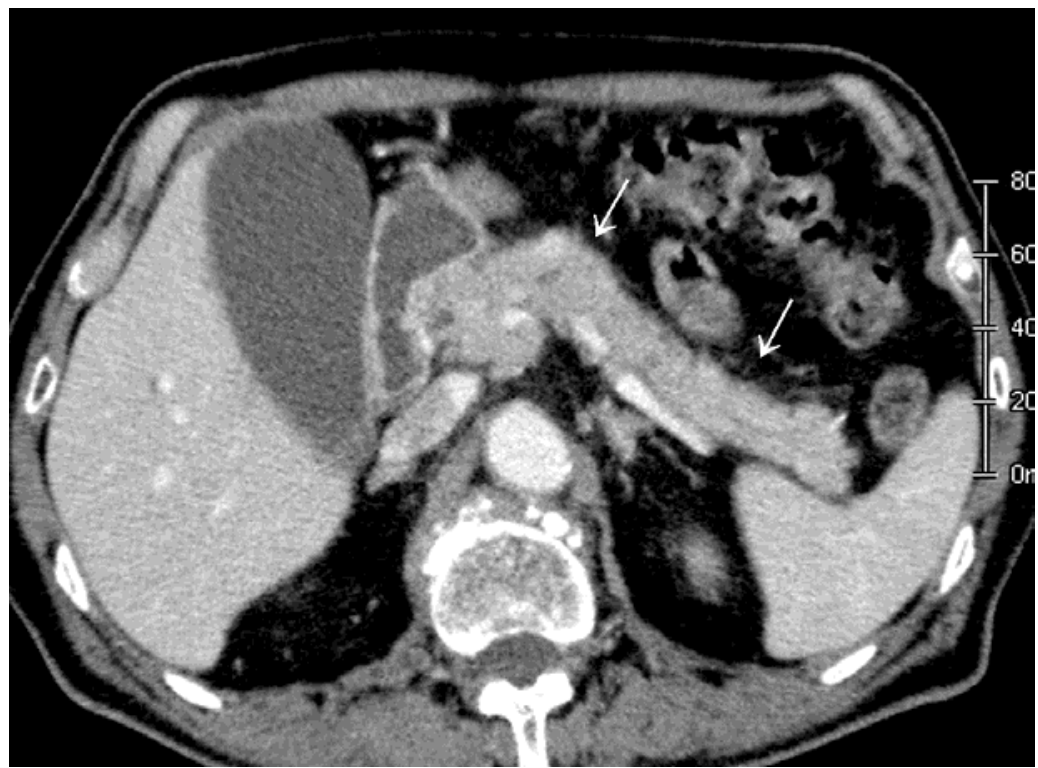

A

A, Contrast enhanced axial CT scan shows diffuse enlargement of the pancreas with sharp borders and minimal peripancreatic stranding (arrow).

Fig. 3. (A) 54-year-old man with diffuse form of AIP. 


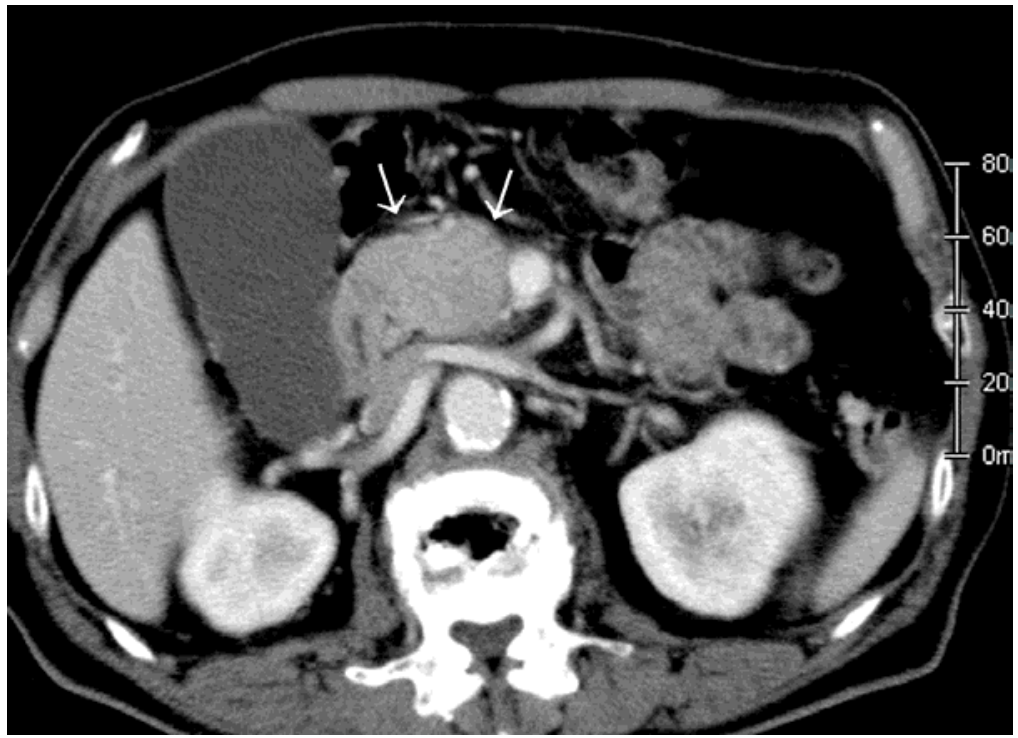

B

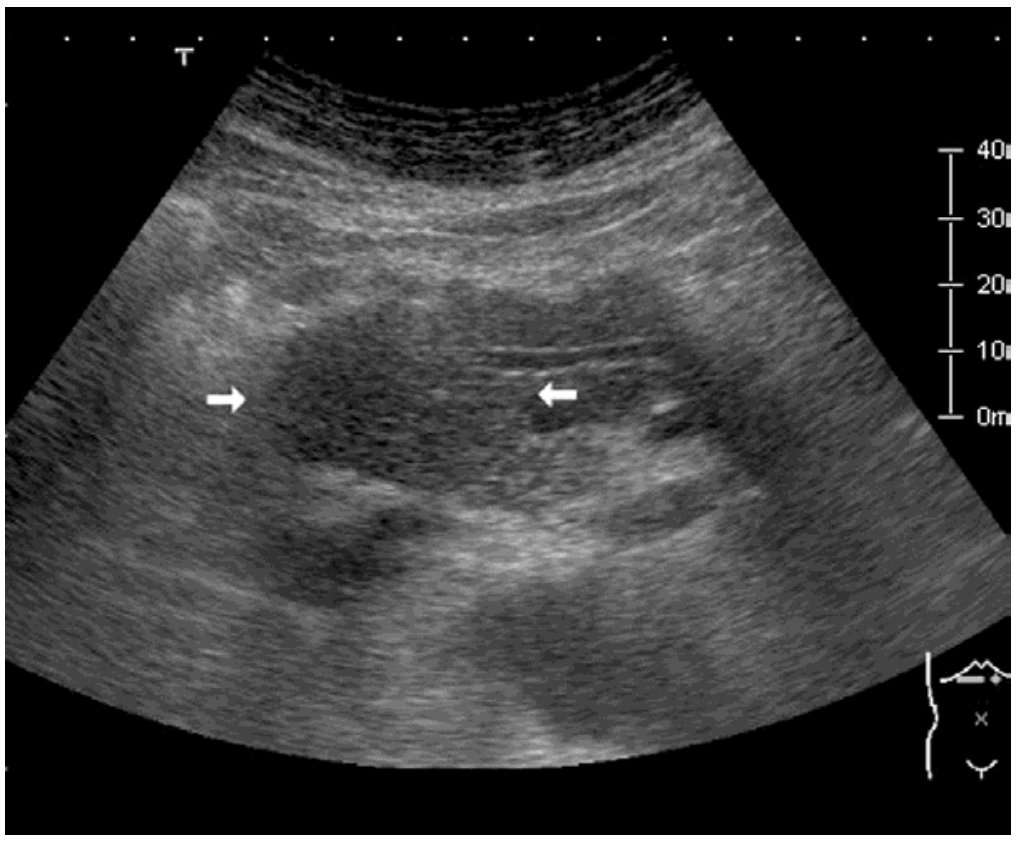

C

B, Swelling of the pancreatic head is also seen (arrow)., C, Transabdominal transverse US image shows enlargement of the pancreatic head with minimal decreased echotexture of pancreas (arrows).

Fig. 3. (B,C) 54-year-old man with diffuse form of AIP. 


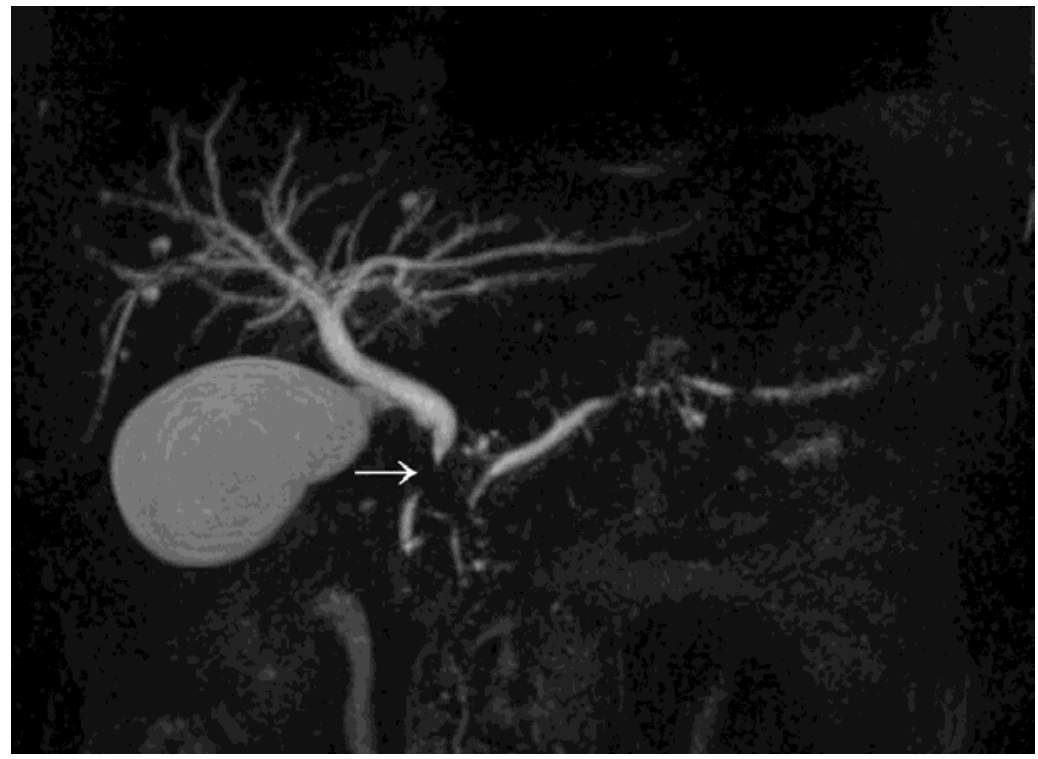

$\mathrm{D}$

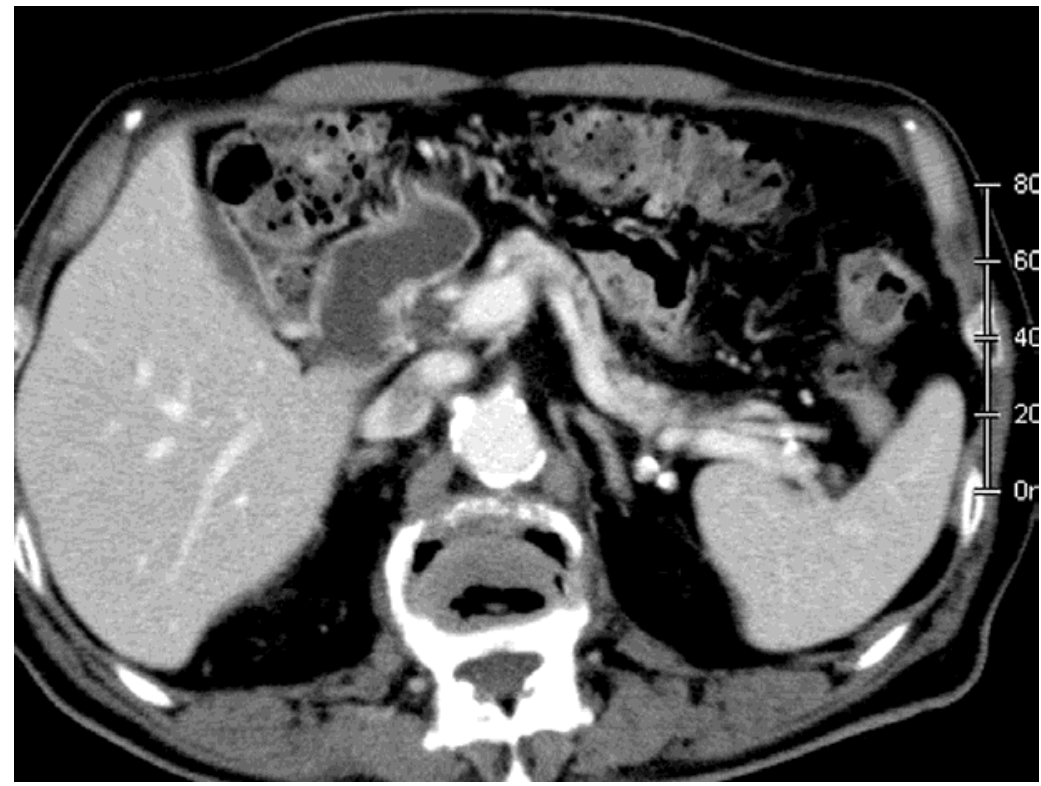

$\mathrm{E}$

D, MRCP image also shows the narrowing of the main pancreatic duct with irregular walls and focal stricture in the distal common bile duct (arrrow),.E, Axial CT scan obtained after steroid therapy shows a normal-appearing pancreas, and enlargement of the pancreas is diminished.

Fig. 3. (D,E) 54-year-old man with diffuse form of AIP. 


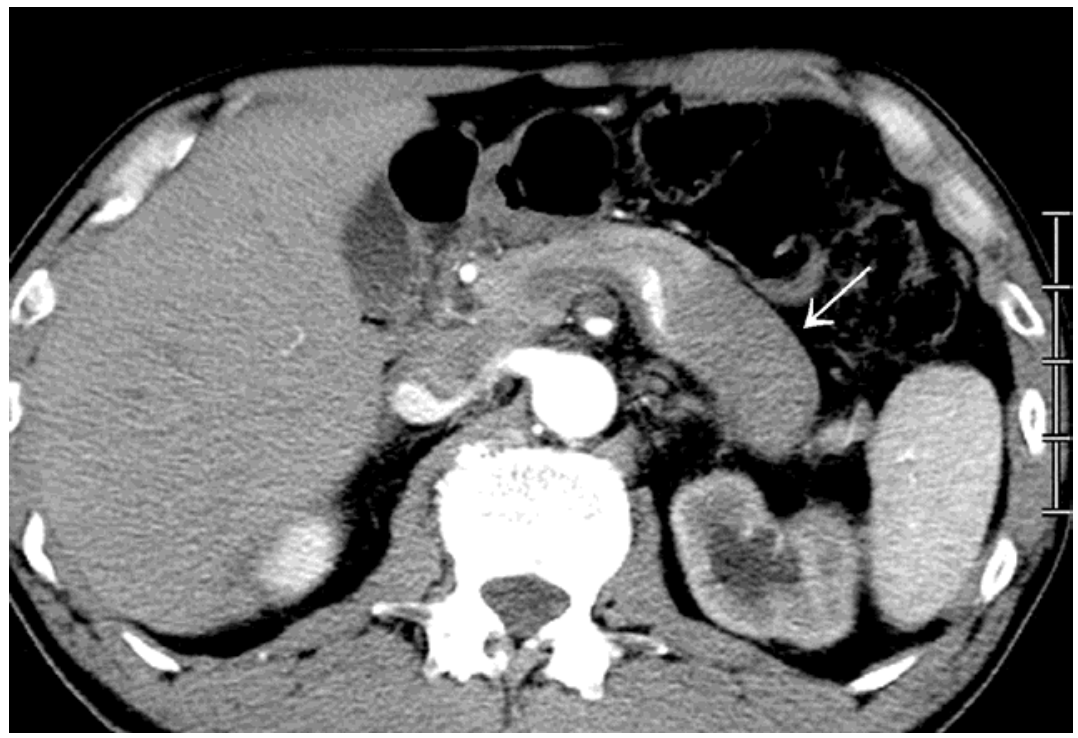

A

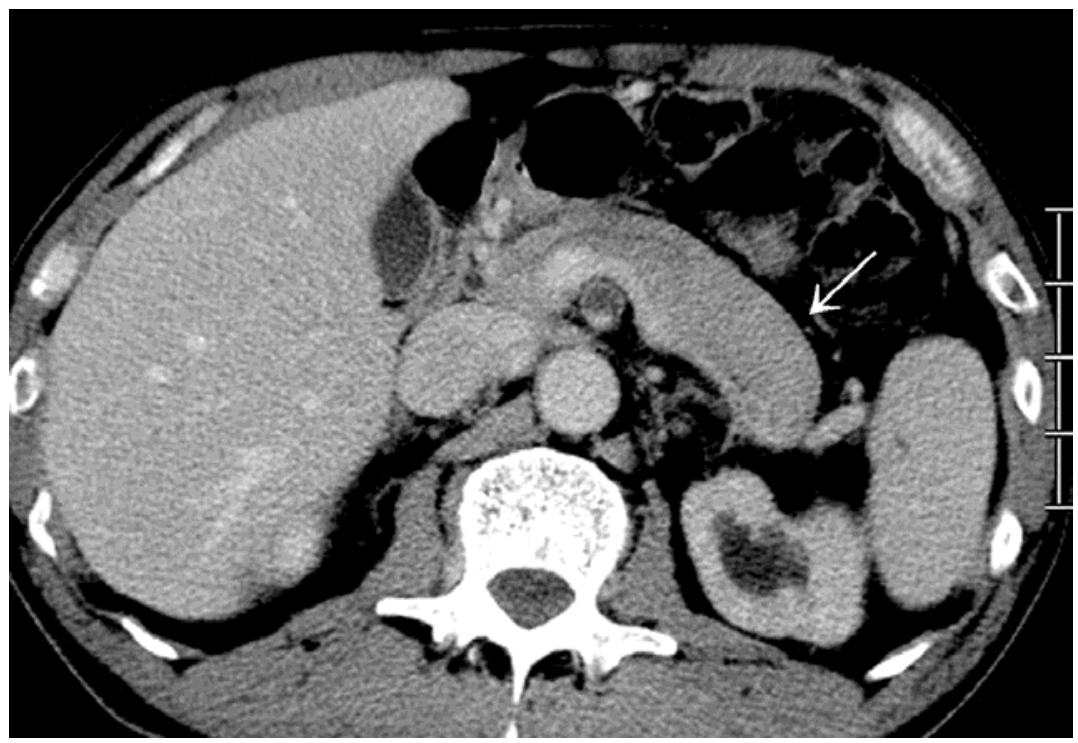

B

Contrast enhanced CT scan shows focal enlargement in the pancreatic body and tail with sharp borders and a thin capsular-like rim. The lesion appears as a relatively low attenuation area compared to normal pancreatic parenchyma on early phase (A), and as an almost iso-attenuation area compared to normal pancreatic parenchyma on delayed phase (B) (arrows). Hydronephrosis on the left is also seen due to concurrent retroperitoneal fibrosis.

Fig. 4. (A,B) 62-year-old man with focal form of AIP. 


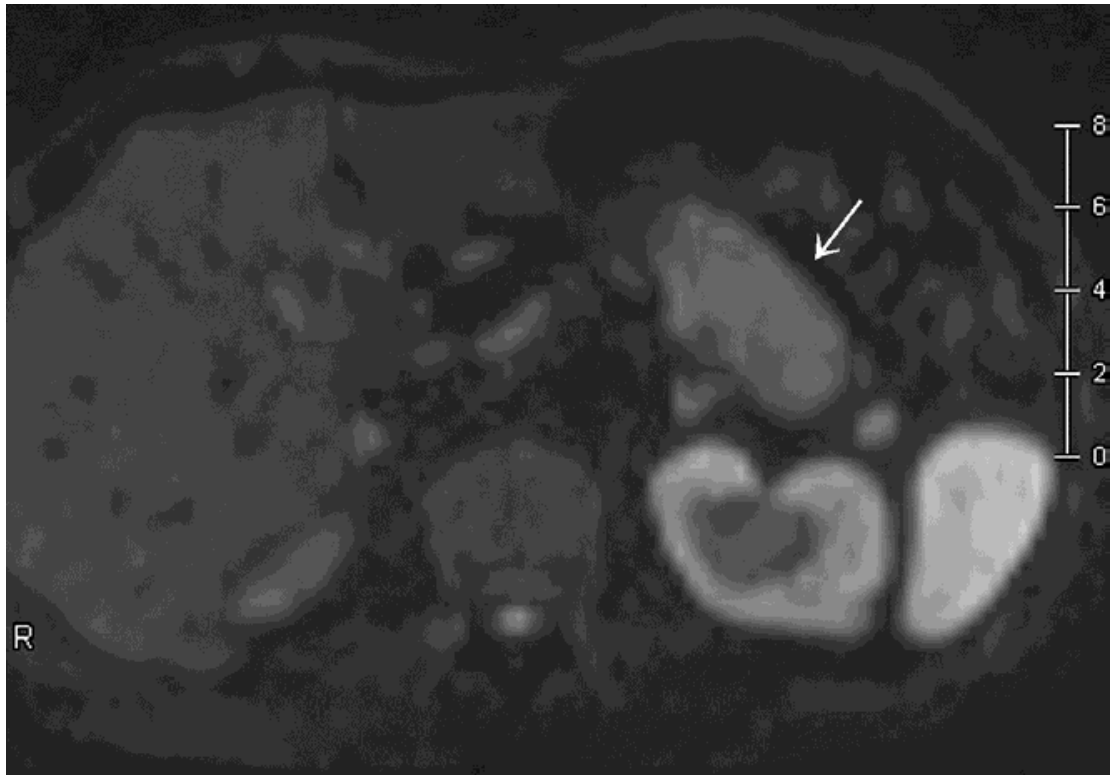

C

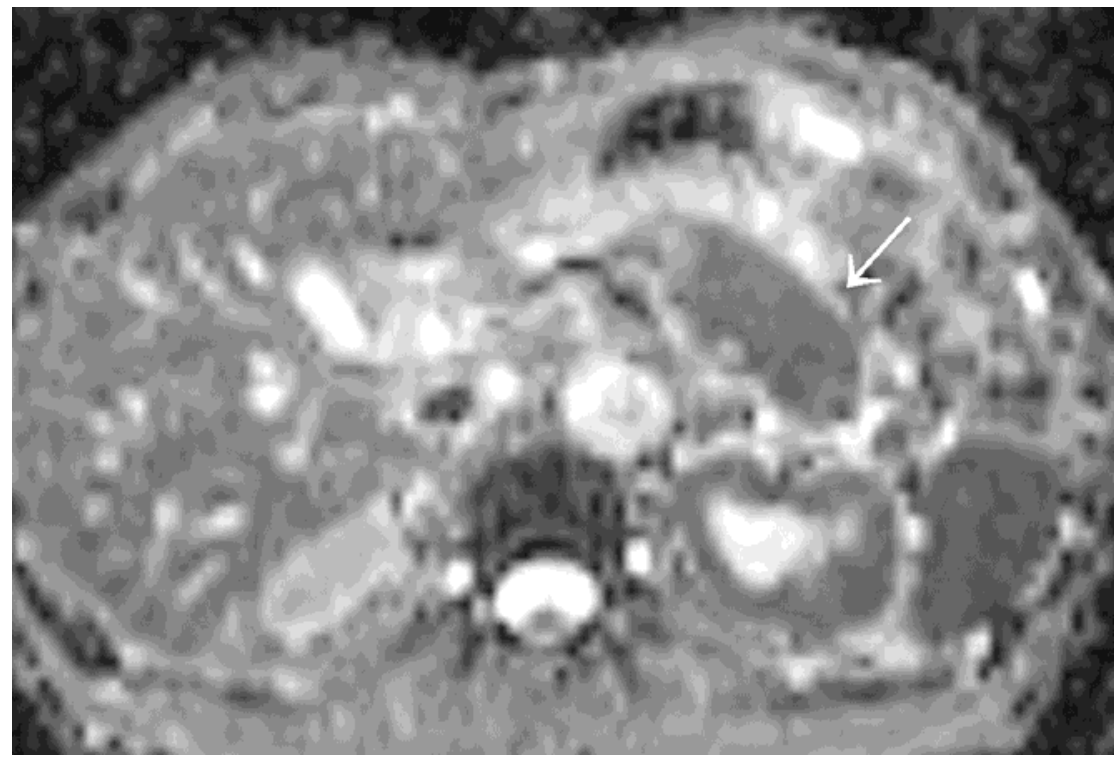

D

C, Diffusion-weighted MR image shows a focal high-intensity area on the pancreatic body and tail (arrow) $\left(\mathrm{b}=800 \mathrm{~mm}^{2} / \mathrm{s}\right)$. D, ADC map shows low ADC value $\left(1.014 \times 10^{-3} \mathrm{~mm}^{2} / \mathrm{sec}\right)$ on the pancreatic body and tail (arrow) .

Fig. 4. (C,D) 62-year-old man with focal form of AIP. 


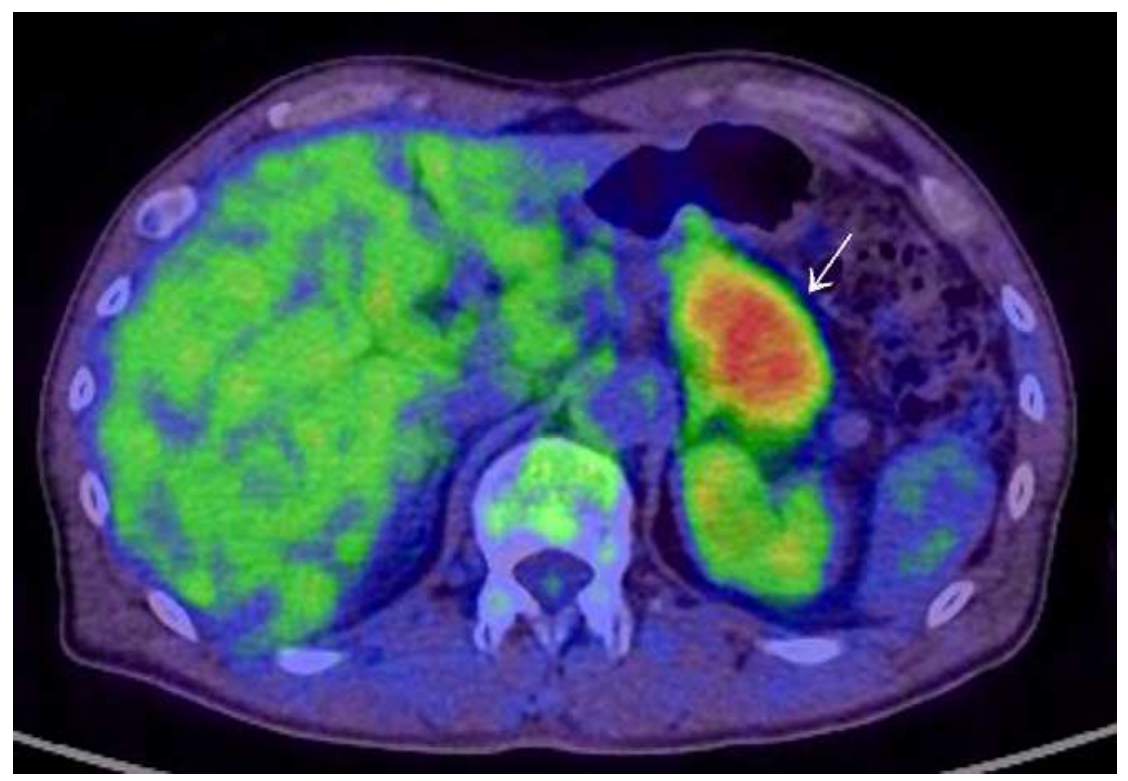

E

E, Combined PET/CT scan shows strong FDG uptake at the pancreatic body and tail (arrow).

Fig. 4. (E) 62-year-old man with focal form of AIP.

FDG-PET/CT is useful for detecting AIP and associated extrapancreatic autoimmune lesions and for monitoring their disease activity. AIP can cause intense FDG uptake in the pancreas (Figure4e). AIP should always be considered when making a diagnosis with FDGPET in patients with pancreatic disorders. In many cases, differentiation of AIP from pancreatic malignancies is thought to be difficult by PET/CT (28-30). Lee et al reported that in difficult cases, on PET/CT imaging, the presence of diffuse uptake of FDG by the pancreas or concomitant extrapancreatic uptake by the salivary glands may aid in differentiation of autoimmune pancreatitis and pancreatic cancer (29).

\section{References}

[1] Finkelberg DL, Sahani D, Deshpande V, Brugge WR. Autoimmune pancreatitis. N Engl J Med 2006; 355:2670.

[2] Okazaki K. Autoimmune pancreatitis is increasing in Japan. Gastroenterology 2003; 125:1557.

[3] Kim KP, Kim MH, Lee SS, et al. Autoimmune pancreatitis: it may be a worldwide entity. Gastroenterology 2004; 126:1214.

[4] Kamisawa T, Egawa N, Nakajima H. Autoimmune pancreatitis is a systemic autoimmune disease. Am J Gastroenterol 2003; 98:2811.

[5] Hirano K, Shiratori Y, Komatsu Y, et al. Involvement of the biliary system in autoimmune pancreatitis: a follow-up study. Clin Gastroenterol Hepatol 2003; 1:453. 
[6] Shinji A, Sano K, Hamano H, et al. Autoimmune pancreatitis is closely associated with gastric ulcer presenting with abundant IgG4-bearing plasma cell infiltration. Gastrointest Endosc 2004; 59:506.

[7] Takeda S, Haratake J, Kasai T, et al. IgG4-associated idiopathic tubulointerstitial nephritis complicating autoimmune pancreatitis. Nephrol Dial Transplant 2004; 19:474.

[8] Saeki T, Saito A, Hiura T, et al. Lymphoplasmacytic infiltration of multiple organs with immunoreactivity for IgG4: IgG4-related systemic disease. Intern Med 2006; 45:163.

[9] Umemura T, Zen Y, Hamano H, et al. Immunoglobin G4-hepatopathy: association of immunoglobin G4-bearing plasma cells in liver with autoimmune pancreatitis. Hepatology 2007; 46:463.

[10] Ghazale A, Chari ST, Zhang L, et al. Immunoglobulin G4-associated cholangitis: clinical profile and response to therapy. Gastroenterology 2008; 134:706.

[11] Raina A, Yadav D, Krasinskas AM, et al. Evaluation and management of autoimmune pancreatitis: experience at a large US center. Am J Gastroenterol 2009; 104:2295.

[12] Tabata M, Kitayama J, Kanemoto H, et al. Autoimmune pancreatitis presenting as a mass in the head of the pancreas: a diagnosis to differentiate from cancer. Am Surg 2003; 69:363.

[13] Erkelens GW, Vleggaar FP, Lesterhuis W, et al. Sclerosing pancreato-cholangitis responsive to steroid therapy. Lancet 1999; 354:43.

[14] Kojima E, Kimura K, Noda Y, et al. Autoimmune pancreatitis and multiple bile duct strictures treated effectively with steroid. J Gastroenterol 2003; 38:603.

[15] Church NI, Pereira SP, Deheragoda MG, et al. Autoimmune pancreatitis: clinical and radiological features and objective response to steroid therapy in a UK series. Am J Gastroenterol 2007; 102:2417.

[16] Sahani DV, Kalva SP, Farrell J, et al. Autoimmune pancreatitis: imaging features. Radiology 2004; 233:345.

[17] Chari ST, Takahashi N, Levy MJ, et al. A diagnostic strategy to distinguish autoimmune pancreatitis from pancreatic cancer. Clin Gastroenterol Hepatol 2009; 7:1097.

[18] Kamisawa T, Egawa N, Nakajima H, et al. Clinical difficulties in the differentiation of autoimmune pancreatitis and pancreatic carcinoma. Am J Gastroenterol 2003; 98:2694.

[19] Eerens I, Vanbeckevoort D, Vansteenbergen W, Van Hoe L. Autoimmune pancreatitis associated with primary sclerosing cholangitis: MR imaging findings. Eur Radiol 2001; 11:1401.

[20] Irie $\mathrm{H}, \mathrm{Honda} H, \mathrm{Baba} S$, et al. Autoimmune pancreatitis: CT and MR characteristics. AJR Am J Roentgenol 1998; 170:1323.

[21] Yang DH, Kim KW, Kim TK, et al. Autoimmune pancreatitis: radiologic findings in 20 patients. Abdom Imaging 2006; 31:94.

[22] Nakazawa T, Ohara H, Sano H, et al. Difficulty in diagnosing autoimmune pancreatitis by imaging findings. Gastrointest Endosc 2007; 65:99.

[23] Frulloni L, Scattolini C, Falconi M, et al. Autoimmune pancreatitis: differences between the focal and diffuse forms in 87 patients. Am J Gastroenterol 2009; 104:2288.

[24] Koga Y, Yamaguchi K, Sugitani A, et al. Autoimmune pancreatitis starting as a localized form. J Gastroenterol 2002; 37:133 
[25] Differentiation of autoimmune pancreatitis from pancreatic cancer by diffusionweighted MRI. Kamisawa T, Takuma K, Anjiki H, et al. Am J Gastroenterol. 2010 Aug; 105(8):1870

[26] Diffusion-weighted magnetic resonance imaging in autoimmune pancreatitis. Taniguchi T, Kobayashi H, Nishikawa K, et al. Jpn J Radiol. 2009 Apr; 27(3):138

[27] Horiuchi A, Kawa S, Hamano H, et al. ERCP features in 27 patients with autoimmune pancreatitis. Gastrointest Endosc 2002; 55:494.

[28] The efficacy of whole-body FDG-PET or PET/CT for autoimmune pancreatitis and associated extrapancreatic autoimmune lesions Nakajo M, Jinnouchi S, Fukukura Y et al. European Journal of Nuclear Medicine and Molecular Imaging. 2007. 34(12), 2088.

[29] Utility of 18F-FDG PET/CT for differentiation of autoimmune pancreatitis with atypical pancreatic Imaging findings from pancreatic cancer. Lee TY, Kim MH, Park DH et al. AJR 2009:193(2); 343. 


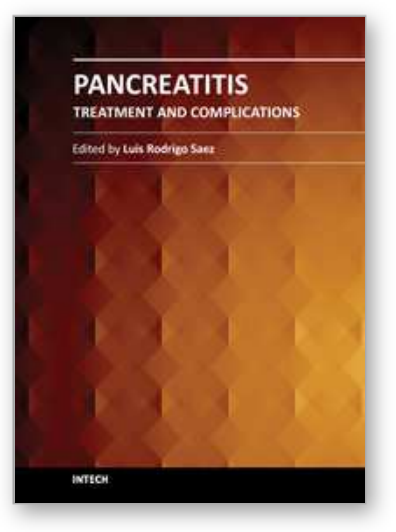

\author{
Pancreatitis - Treatment and Complications \\ Edited by Prof. Luis Rodrigo
}

ISBN 978-953-51-0109-3

Hard cover, 212 pages

Publisher InTech

Published online 02, March, 2012

Published in print edition March, 2012

Pancreatitis may be acute or chronic. Although they can be caused by similar aetiologies, they tend to follow distinct natural histories. Around $80 \%$ of acute pancreatitis (AP) diagnoses occur as secondary to gallstone disease and alcohol misuse. This disease is commonly associated with the sudden onset of upper abdominal that is usually severe enough to warrant the patient seeking urgent medical attention. Overall, 10 to $25 \%$ of AP episodes are classified as severe, leading to an associated mortality rate of 7 to $30 \%$. Treatment is conservative and consists of general medical support performed by experienced teams, sometimes in ICUs. Although most cases of acute pancreatitis are uncomplicated and resolve spontaneously, the presence of complications has significant prognostic importance. Necrosis, hemorrhage, and infection convey rates of up to $25 \%, 50 \%$, and $80 \%$ mortality, respectively. Other complications such as pseudocyst formation, pseudoaneurysm formation, or venous thrombosis increase morbidity and mortality to a lesser degree. The presence of pancreatic infection must be avoided.

\title{
How to reference
}

In order to correctly reference this scholarly work, feel free to copy and paste the following:

Koji Takeshita (2012). Imaging Appearances of Autoimmune Pancreatitis, Pancreatitis - Treatment and Complications, Prof. Luis Rodrigo (Ed.), ISBN: 978-953-51-0109-3, InTech, Available from: http://www.intechopen.com/books/pancreatitis-treatment-and-complications/imaging-appearances-ofautoimmune-pancreatitis

\section{INTECH}

open science | open minds

\section{InTech Europe}

University Campus STeP Ri

Slavka Krautzeka 83/A

51000 Rijeka, Croatia

Phone: +385 (51) 770447

Fax: +385 (51) 686166

www.intechopen.com

\section{InTech China}

Unit 405, Office Block, Hotel Equatorial Shanghai

No.65, Yan An Road (West), Shanghai, 200040, China

中国上海市延安西路65号上海国际贵都大饭店办公楼 405 单元

Phone: +86-21-62489820

Fax: $+86-21-62489821$ 
(C) 2012 The Author(s). Licensee IntechOpen. This is an open access article distributed under the terms of the Creative Commons Attribution 3.0 License, which permits unrestricted use, distribution, and reproduction in any medium, provided the original work is properly cited. 